\title{
Research Paper: State Investment and Empowerment of Local Communities, An Approach to Sustainable Rural Development (Experience of Kashan Rural Area in Central Iran)
}

\author{
Mustafa Taleshi ${ }^{1}$, Mohsen Shaterian², Mahmoud Ganjipour ${ }^{3 *}$ \\ 1. Professor, Department of Geography, Department of Postgraduate, Payamnoor University, Tehran, Iran. \\ 2. Professor, Department of Geography and Ecotourism, Faculty of Natural Resources and Earth Sciences, Kashan University, Kashan, Iran. \\ 3. PhD Student, Department of Geography, Department of Postgraduate, Payamnoor University, Tehran, Iran.
}

\begin{tabular}{|l|l|}
\hline $\begin{array}{l}\text { Use your device to scan } \\
\text { and read the article online }\end{array}$ & $\begin{array}{l}\text { Crtation: Taleshi, M., Shaterian, M., \& Ganjipour, M. (2020). State Investment and Empowerment of Local Communities, An } \\
\text { Approach to Sustainable Rural Development (Experience of Kashan Rural Area in Central Iran). Journal of Sustainable Rural } \\
\text { Development, 4(2), 229-242. https://doi.org/10.32598/JSRD.4.2.10 }\end{array}$ \\
dol: : $:$ https://doi.org/10.32598/JSRD.4.2.10
\end{tabular}

\section{Article info:}

Received: 23 Nov. 2019

Accepted: 10 June 2020

Keywords:

Empowerment, State Investment, Rural, Capacity Building, Kashan

\section{ABSTRACT}

Purpose: The empowerment approach is considered as one of the efficient approaches in rural development activities in Iran through the rural planning system within the framework of fiveyear programs with government investment in order to achieve sustainable rural development. In the present research, the role of government investments in empowering villagers and their effectiveness in the rural area of Kashan was studied.

Methods: In the present research, descriptive-analytical research method was employed and sample population was selected using three-dimensional matrix method of government investment, village location and rural population of 12 villages and 316 rural households. To explain the relationships between independent and dependent variables, Pearson correlation inappropriate statistical environments and for modeling effects, the structural equation model (SEM) in AMOS software was used.

Results: Findings indicate a strong, positive and direct relationship between the two variables of investment and rural empowerment $(\mathrm{P}=0.000)$. As the amount of investment increases, the empowerment of the villagers also increases. The structural equation model showed that government investment with a factor load of 0.072 has an effect on rural empowerment (RMSEA $=0.036$ ).

Conclusion: Based on the research results, to achieve sustainable rural development, the empowerment approach should be considered as a goal and not a tool. In the experience of government investment in the rural area of Kashan in central Iran, the investment process was relatively effective and in the future, regarding the investment process and implementation of rural projects in general and in arid and semi-arid areas in particular, empowerment and institutionalization approach in villages should be considered. 


\section{Introduction}

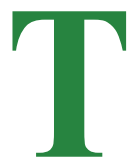

here is a general agreement in the development literature of Third World countries about the importance of the state in advancing the development process and it is one of the forces that play a great role in the processes of change of these societies, including in the field of rural change. Therefore, the nature of states, political and ideological philosophy and their structure play a key role in the development process, including rural development (Shakoori, 2005). Today, one of the common assumptions in scientific circles and rural management is that "rural development" in so-called "developing" countries is possible without "state" involvement (Kohli, 2004). In general, the rural development approach in developing countries, which is influenced by the classical theories of development management, is usually a development that is designed, managed and implemented with a broad role of state and with titles such as "state-centered development" or "top-bottom development" (Assche et al., 2014). The operating state in this type of development is also referred to as "developmental state" or "strong state" (Kumar, 2004). Hence, the prevalence of classical development theories in developing countries in recent decades has posed many challenges in terms of rural development (Michalek \& Zarnekow, 2012; Kumar, 2004; Simard et al., 2017; Shafiei Sabet et al., 2018; Shafiei Sabet et al., 2019). As in most developing countries, rural development in Iran is a process with a dominant role of the state (Azad, 2000; Ebrahim Bay Salami, 2007; Amir Ahmadi, 2002; Evans, 2001; Jalaeipour, 2014). Since the formation of the centralized state in Iran and after 1927, planning has begun in its current form, and after 60 years, 12 programs have been prepared in the country, of which 11 have been implemented. Before the Revolution (1978), 6 programs were prepared and 5 programs were implemented. After the revolution, 6 programs were prepared and 5 programs were implemented, and the sixth program is nearing completion. In Iran, during the past decades, most of the stages of rural development took place within the framework of macro development programs. These programs determine the direction of state measures in various fields by identifying the activities and axes of macro and micro measures. The field of rural society is one of these areas of planning in which the state implements measures at various levels based on short and medium term plans (Saeedi \& Darabi, 2006). State interventions in the rural areas are manifested with the arrival of investments and can have a decisive effect on the fate of these communities. In other words, as a result of these investments, at least part of the problems of rural settlements mentioned in development programs should be reduced or eliminated, and on the other hand, the necessary platform for rural development should be provided.

Now, according to the issues raised, it can be stated that if the village is assumed as a system, the introduction of a new variable will lead to changes in this system. The state expects these changes to empower villagers. But there is no requirement that the influx of investment into the villages will lead to the empowerment of the villagers and can have quite the opposite effect. But was what actually took place in the country's villages homogeneous with the demands and goals of the programs? In other words, considering the high volume of credits that are spent every year in rural settlements, the question can be raised that what does investing in rural settlements have to do with empowering the villagers? Has the influx of investments into the villages as a factor of change been able to create the necessary changes and transformations in order to empower the villagers?

In this context, considering that the state has taken various measures to empower and develop the villages in the area to date, this study seeks to examine the mechanism of investment in the villages, and on the other hand, the role of empowering the people, and how they are affected in the villages of Kashan region in Central Iran, and thus achieve a suitable mechanism for intervention in the villages.

\section{Literature Review}

Since the 1970s, the role of the state in development has been strongly emphasized. Given that different types of state structures create different capacities for action, it is this structure that determines the range of roles that the state can play (Evans, 2001). Given the definition that the state is an institution formed of monopoly power to play a specific social role in a geographical area, the roles that the state can accept are very different and diverse. These ideas and the extent of the role of the state and its interventions in development have been different over the years (Rand, 2004). Considering the set of roles and functions of states in the Third World, three groups of states can be identified that can be classified based on the extent of their involvement in the development process and their achievement of development: a) developmental states; b) intermediate states; and c) states careless about development. Meanwhile, a country like Iran can be placed in the middle class. Because according to the definition, the state seeks development based on its different programs. Therefore, the role and importance of 
the state in the development process (or its deterrence) is undeniable. These points can be seen in the nature of the states of oil-exporting countries, known as "rentier states" or "semi-rentier states". These states, while independent of society, have not been very successful in terms of development (Shakoori, 2004).

Until 1970, rural management approach in most countries of the world was influenced by the dominance of top-down policies and approaches to development management, which followed the emergence of environmental challenges and socio-economic inequalities, It has been provided the field of attention and change of development approach to bottom-up since the 1980s to balance rural settlements (Healey, 2000; Waas et al., 2014). Therefore, changing the approach from top-down rural development strategies to bottom-up approach in rural development includes both a change in the way rural management is managed and a change in the type of activities to promote development. In contrast to public administration (top-down approach), bottom-up rural development is pursued by local communities, and active and real participation of local communities can lead to sustainable development (Zasada et al., 2017; Waligo et al., 2013; Rossberger \& Krause, 2014). In other words, state responsibility shifts from the provider of rural development to the facilitator of rural reconstruction (Moseley, 2003). The bottom-up approach is dramatically supported by both rural development professionals and neoliberal politicians working to rebuild the state. In terms of the first group, a bottom-up approach leads to the empowerment of local communities and the development of revitalization strategies and is tailored to local needs and the environment. In terms of the second group, a bottom-up approach shifts the responsibility for rural development from state to citizens, and the state reduces the cost of rural development.

In recent decades, new development programs introduced a new model of rural development that seeks to revitalize rural areas by improving and increasing the value of local resources, both natural and human, according to the priorities and preferences of the local community (Woods, 2011). Literally, the new paradigm is based on the principle of empowerment of rural communities (Amundsen \& Martinsen, 2015). Empowerment is defined in the Oxford English Dictionary as empowering people (Steel, 2010). The concept of empowerment originated in the 1950s and peaked in the 1970s. In the 1990s, it dominated rural development theories. In this regard, Thomas Slater has defined empowerment as follows: Empowerment is the process of expanding the existing capabilities and capacities to par- ticipate in dialogue, negotiate and control the institutions and organizations that have an impact on the life of rural communities (Shahraki, 2014). Using a village-based definition, empowerment in the operational approach means capacity building among villagers to play an effective role in the process of sustainable rural development (Razavi, 2011: 30). In the Glossary of Geography and Planning, empowerment means the distribution of power, information, knowledge and rewards in organizations, institutions, communities and the business environment, the living space and human settlements (Rokneddin Eftekhari et al., 2017: 7).

Empowerment, depending on the power structure, can be productive (passive participation) or unproductive (active participation). Thus, inequality in the distribution of power causes an imbalance in the views and opinions of the areas involved in the management and planning process, and changes in the power structure in order to empower local communities can make them selfreliant for local management (Giampiccoli \& Mtapuri, 2012). It can also be said that empowerment is a process through which people have more control over their affairs and by gaining high power, control over resources, building trust, capacity building and active participation can lead their lives in the right direction. Empowerment strategies are helping people to play an active role in their cognition (Rifkin, 2003). Empowerment is part of the language of development and is a fundamental human right and a fundamental principle in development (Cumming \& Worley, 2014). It can be said that the main goal of empowering rural society is its development and excellence, and one of the indicators for measuring the development of any country is the level of empowerment of the poor and villagers (Sharma, \& Gupta, 2017).

Therefore, in the context of development, the concept of empowerment has been studied with two approaches: A) "Motivational Empowerment " approach; in this approach, the goal is to empower and strengthen selfconfidence; B) cognitive approach to empowerment; this approach broadly defines empowerment as a state of intrinsic motivation that includes five inner feelings: 1- Competence: A person believes in his ability and capacity to do things, 2- Impact: It is the extent to which a person has the ability to influence the consequences of his work, 3- Trust: People feel that they are treated fairly and equally, 4- Self-determination: It is an individual feeling about the right to choose to organize activities and 5- Meaning: The person considers the task he performs to be meaningful and valuable (Fernandez \& Moldogaziev, 2015) 
Empowerment, depending on the power structure, can be productive (passive participation) or unproductive (active participation). Therefore, inequality in the distribution of power causes an imbalance in the views and opinions of the areas involved in the management and planning process, and a change in the power structure in order to empower local communities can make them self-reliant for local management (Giampiccoli \& Mtapuri, 2012). Thus, the adoption of appropriate policies to invest in rural community empowerment methods for rural participation is one of the most important factors in the development of rural areas (Chen et al., 2016).

According to the issues raised, it can be said that government investment approaches in rural areas should pay attention to all rural aspects (ecological, economic, social and physical space), while emphasizing the aspects of empowerment based on collective actions and decisions, as one of the most important factors and think about strengthening its foundations in rural areas and provide the ground for the development of rural settlements.

\section{Methodology}

The research method of this article is descriptive-analytical and it is based on quantitative and qualitative methods. The statistical population of this study includes all 15255 rural households (Statistical Center of Iran, 2016) who live in 67 villages of Kashan district. The sample size was determined based on Cochran's method from 316 rural households (Saraei, 2003: 129). To collect field information, the samples were selected in two stages: a) non-probability cluster sampling b) judgmental sampling. Accordingly, in order to determine the sample using the non-probability cluster sampling method, the optimal distribution and coverage of the samples were considered. Therefore: a) The selected sample should be scattered in the whole area of Kashan; B) The selected sample should cover the amount of different state investments in the villages of the district. Thus, in this study, the amount of state investment as the main indicator and the position and population as sub-indicators were considered to determine the sample villages and a total of 12 villages were selected as the sample. In this article, SPSS software was used to assess the validity and reliability of the questionnaire. Using the KMO test, the validity of the rural household head questionnaire to measure the level of rural empowerment is equal to 0.867 and the validity of the rural household head questionnaire to measure state investment is equal to 0.826 . Also, based on the results of the structural validity test, Cronbach's alpha coefficient obtained from the rural household heads questionnaire to measure the level of rural empowerment is equal to 0.974 and the rural household heads questionnaire to measure state investment is equal to 0.846 . Thus, the validity and reliability of the questionnaire are confirmed. To explain the relationship between the independent and dependent variables according to the nature of the hypotheses, Pearson correlation in SPSS software and to explain and model the effects, the structural equation model (SEM) in AMOS software was used.

\section{Study area}

In this research, the Kashan region constitutes the study area. Therefore, the study area is located at latitude $33^{\circ}$ 28 to $34^{\circ} 30^{\prime}$ minutes and longitude $50^{\circ} 52^{2}$ to $52^{\circ} 25^{\prime}$. In terms of political divisions, this area includes two cities of Kashan and also Aran and Bidgol (Figure1). Accordingly, the study area includes 6 counties and 11 rural districts. In this area, there are 67 villages and 11 cities. In 2016, from the total population of 462002 people in the Kashan region, 90.1\% lived in urban areas and 9.8\% in rural areas, which indicates that urbanization in the Kashan region has reached its peak. Therefore, it can be said that a population of 45737 people (15255 households) live in villages of the Kashan region (Statistical Center of Iran, 2016).

A look at the distribution of rural settlements shows that most of them $(38.8 \%)$ are located in the foothills. Desert villages $(22.3 \%)$ are second. The share of mountain villages is $20.8 \%$ of the villages in the area and $17.9 \%$ of the villages in the area are located in the plains. The study of the rural population shows that although $22 \%$ of villages are located on the edge of the desert, this part includes $35.4 \%$ of households and $37.3 \%$ of the rural population of the area. In other words, the villages on the edge of the desert are large, so although their number is limited, they have a larger population (Figure 2).

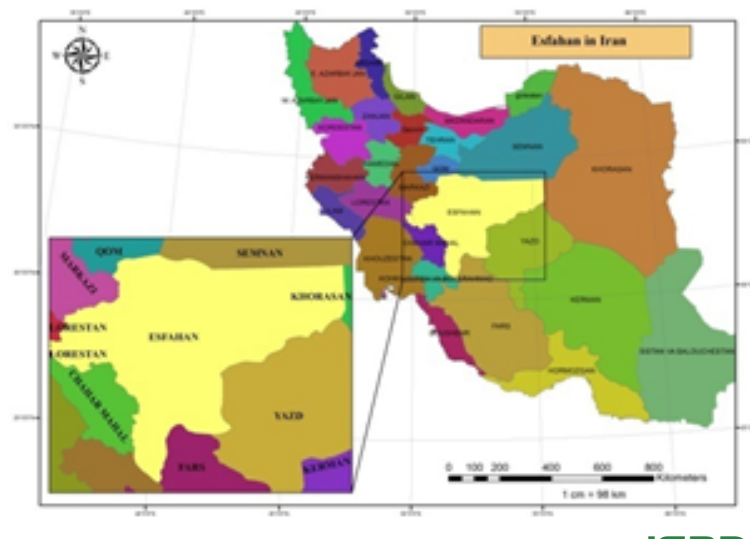

Figure 1. Location of Esfahan in Iran 


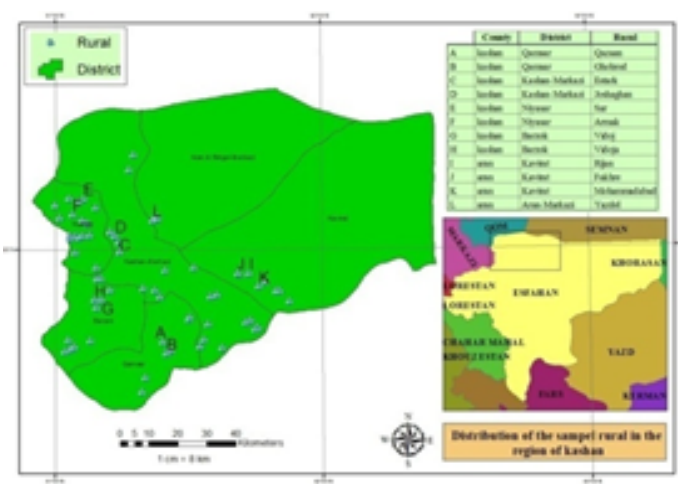

Figure 2. Distribution of the rural sample with respect to investment, population and position in the area of Kashan

\section{Findings}

Measurement models: Confirmatory factor analysis and validation of scales

\section{State investment and rural empowerment}

First, nine single-factor confirmatory factor analysis (CFA) models for creating and measuring the validity of four subscales of ecological, economic, social and physical-spatial dimensions as components of state investment and five subscales of self-determination, competence, meaning, impact and trust as components of rural empowerment were mapped and analyzed in Amos software environment.
Figure 3 and Figure 4 show the path diagrams of these nine scales for the relevant reagents or observed variables, along with standard estimates of regression coefficients, Chi-square index, and its significance level. The variable e represents the measurement error of the 39 observed variables. Table 1 and Table 2 also show these standard estimates of the path coefficient, along with critical ratios, standard error (SE) and significance level (P-value).

It is observed that all observation variables (except cost and access to services) have positive and significant regression coefficients with their scales and the magnitude of these coefficients (factor effects) is relatively high for all cases.
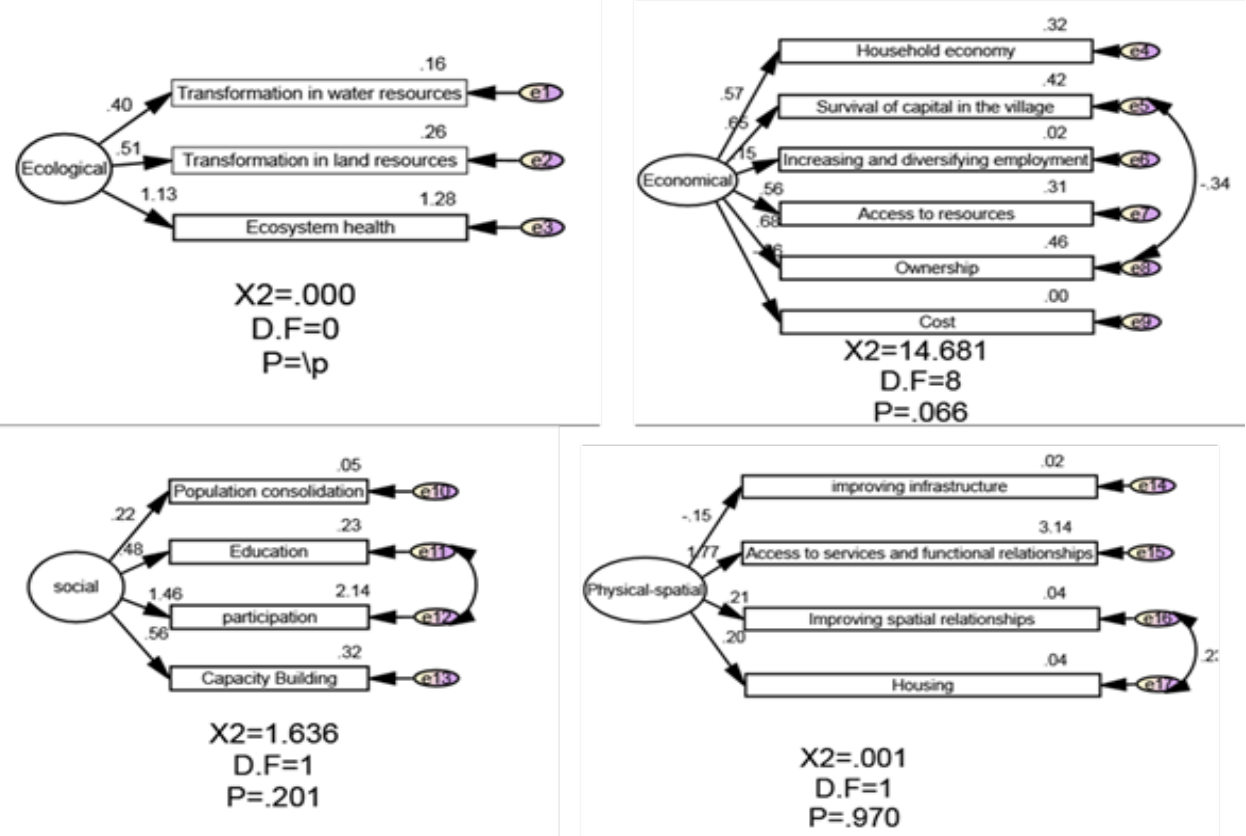

Figure 3. Standard estimates of confirmatory factor models for the validation of the four scales of state investment 9 JSRD 

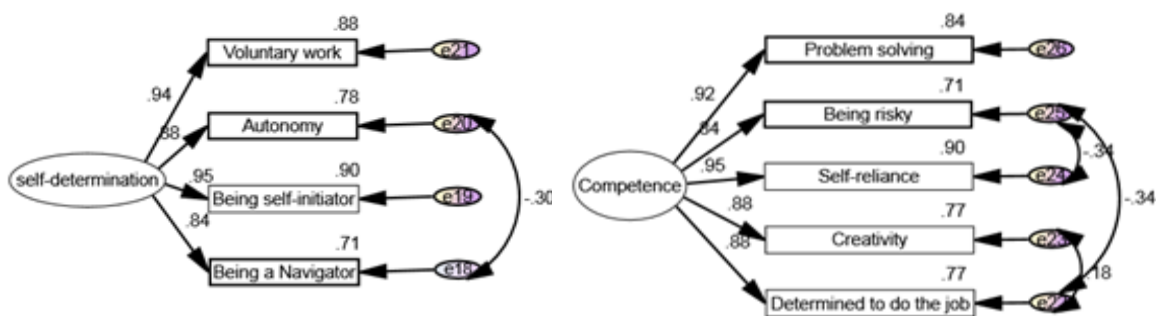

$\mathrm{X} 2=.443$

D. $F=1$

$\mathrm{X} 2=1.005$

$P=.506$

D. $F=2$

$\mathrm{P}=.605$
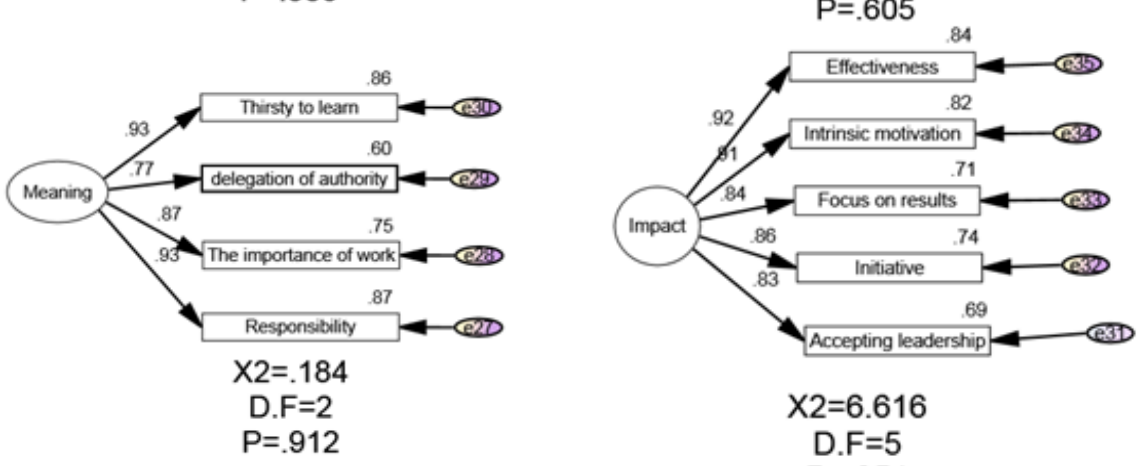

$\mathrm{X} 2=6.616$

D. $F=5$

$\mathrm{P}=\mathbf{2 5 1}$

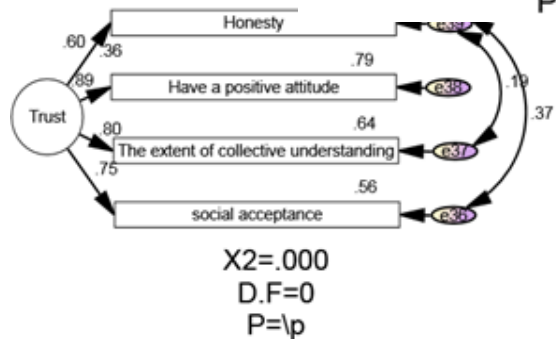

Figure 4. Standard estimates of confirmatory factor models for validation of five scales of villagers' empowerment

Table 1. Standard estimates and significance level of factor loads of state investment sub-scales components

\begin{tabular}{|c|c|c|c|c|c|}
\hline & \multicolumn{5}{|c|}{ Measured variables and indicators (observed indicators) } \\
\hline & Component & Estimate & S.E. & C.R. & $\mathbf{P}$ \\
\hline \multirow{3}{*}{ Ecological } & Transformation in water resources & 1.000 & & & \\
\hline & Transformation in land resources & 1.306 & .184 & 7.103 & $* * *$ \\
\hline & Ecosystem health & 3.897 & .954 & 4.083 & $* * *$ \\
\hline \multirow{6}{*}{ Economic } & Household economy & 3.023 & 1.366 & 2.213 & .027 \\
\hline & Survival of capital in the village & 3.853 & 1.804 & 2.136 & .033 \\
\hline & Increasing and diversifying employment & 1.000 & & & \\
\hline & Access to resources & 3.718 & 1.658 & 2.243 & .025 \\
\hline & Ownership & 4.941 & 2.229 & 2.217 & .027 \\
\hline & Cost & -.327 & .401 & -.815 & .415 \\
\hline \multirow{4}{*}{ Social } & Population consolidation & 1.000 & & & \\
\hline & Education & 1.826 & .872 & 2.095 & .036 \\
\hline & Participation & 6.604 & 2.895 & 2.281 & .023 \\
\hline & Capacity building & 2.578 & .462 & 5.575 & $* * *$ \\
\hline \multirow{4}{*}{ Physical-spatial } & Improving infrastructure & -.605 & .157 & -3.865 & $* * *$ \\
\hline & Access to services and functional relationships & 6.470 & 8.946 & .723 & .470 \\
\hline & Improving spatial relationships & 1.000 & & & \\
\hline & Housing & .931 & .171 & 5.441 & $* * *$ \\
\hline
\end{tabular}


Table 2. Standard estimates and significance level of factor loads of villagers' empowerment sub-scales components

\begin{tabular}{|c|c|c|c|c|c|}
\hline & \multicolumn{5}{|c|}{ Measured variables and indicators (observed indicators) } \\
\hline & Component & Estimate & S.E. & C.R. & $\mathbf{P}$ \\
\hline \multirow{4}{*}{ Self-determination } & Voluntary work & 1.000 & & & \\
\hline & Autonomy & .941 & .036 & 26.204 & $* * *$ \\
\hline & Being self-initiator & .915 & .027 & 34.204 & *** \\
\hline & Being a navigator & .836 & .036 & 23.234 & $* * *$ \\
\hline \multirow{5}{*}{ Competence } & Problem solving & 1.024 & .034 & 30.199 & *** \\
\hline & Being risky & .857 & .042 & 20.610 & $* * *$ \\
\hline & Self-reliance & 1.000 & & & \\
\hline & Creativity & .958 & .037 & 25.937 & $* * *$ \\
\hline & Determined to do the job & .910 & .035 & 25.788 & $* * *$ \\
\hline \multirow{4}{*}{ Meaning } & Eager to learn & 1.000 & & & \\
\hline & Delegation of authority & .900 & .048 & 18.566 & $* * *$ \\
\hline & The importance of work & 1.005 & .042 & 23.665 & $* * *$ \\
\hline & Responsibility & .999 & .035 & 28.508 & $* * *$ \\
\hline \multirow{5}{*}{ Impact } & Effectiveness & .988 & .046 & 21.660 & $* * *$ \\
\hline & Intrinsic motivation & .988 & .046 & 21.294 & $* * *$ \\
\hline & Focus on results & 1.000 & & & \\
\hline & Initiative & .919 & .047 & 19.495 & $* * *$ \\
\hline & Accepting leadership & .803 & .044 & 18.354 & $* * *$ \\
\hline \multirow{4}{*}{ Trust } & Honesty & .977 & .086 & 11.300 & $* * *$ \\
\hline & Having a positive attitude & .970 & .067 & 14.559 & $* * *$ \\
\hline & The extent of collective understanding & 1.000 & & & \\
\hline & Social acceptance & .858 & .063 & 13.579 & *** \\
\hline
\end{tabular}

As can be seen, in these tables, a significant level for factor loads or standard regression coefficients of 9 variables is observed, including transformation in water resources, increasing and diversifying employment, population consolidation, improving spatial relationships, voluntary work, self-reliance, eagerness to learn, focus on results and extent of collective understanding not reported. This is because these variables are considered as reference variables (or indicator markers) for the nine hidden ecological, economic, social, physical-spatial, self-determination, competence, significance, impact and trust variables, respectively, in order to eliminate these hidden variables without scale, in other words, without their root and unit of measurement. The last part of the output of factor model analysis to assess the validity of state investment dimension scales and rural empowerment is the fit index of these models. Table 3 shows the values of some of the fittest indicators of 9 subscales of ecological, economic, social, physical-spatial, self-determination, competence, meaning, impact and trust along with their standard values for decision making.
As can be seen, all ten of the above indicators confirm the validity and excellent fit of all 9 models with aggregated data. In this way, the ground is prepared for the formulation and evaluation of the main research model. The most important indicator among these is perhaps the Chi-square. The smaller the Chi-square, the more the model fits with the data. The basis for calculating this index is the difference between the sample variancecovariance matrix obtained from the observed variables and the variance-covariance matrix reproduced based on the estimated parameters in the developed model. The first matrix is actually an estimate of the variance and covariance of research variables in the study population and the second matrix is an estimate of the variancecovariance structure of these variables in an unlimited statistical population. Therefore, having levels of significance of Chi-square values higher than 0.05 (both in measurement models and structural models) means no significant difference or proximity of the values of these two matrices and is a sign of the desirability and validity of the model and is considered the basis of the collected data. 
Table 3. Fit indicators for measuring models of nine subscales of state investment and rural empowerment

\begin{tabular}{|c|c|c|c|c|c|c|c|c|c|c|c|c|}
\hline & \multicolumn{12}{|c|}{ Fit indicators } \\
\hline & $\sum_{U}^{z}$ & 㟔 & $a$ & $\Xi$ & $\overline{\bar{z}}$ & 苞 & 芯 & $\sum_{\propto}^{\overleftarrow{山}}$ & 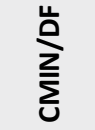 & $\overline{\underline{x}}$ & $\bar{\Xi}$ & ㅍ \\
\hline Ecological & 0.000 & 0 & & & 1.000 & & 1.000 & & & & 1.000 & 1.000 \\
\hline Economic & 14.68 & 8 & 0.066 & 0.93 & 0.92 & 0.95 & 0.98 & 0.051 & 1.8 & 0.86 & 0.96 & 0.96 \\
\hline Social & 1.6 & 1 & 0.201 & 0.99 & 0.99 & 0.99 & 0.97 & 0.045 & 1.6 & 0.97 & 0.99 & 0.99 \\
\hline Physical-spatial & 0.001 & 1 & 0.970 & 1.000 & 1.000 & 1.000 & 1.000 & 0.000 & 0.001 & 1.000 & 1.000 & 1.000 \\
\hline $\begin{array}{l}\text { Self-determina- } \\
\text { tion }\end{array}$ & 0.443 & 1 & 0.506 & 1.000 & 1.000 & 0.99 & 0.99 & 0.000 & 0.443 & 0.99 & 1.000 & 1.000 \\
\hline Competence & 1 & 2 & 0.605 & 1.000 & 0.99 & 0.99 & 0.99 & 0.000 & 0.503 & 0.99 & 1.000 & 1.000 \\
\hline Meaning & 0.184 & 2 & 0.912 & 1.000 & 1.000 & 0.99 & 1.000 & 0.000 & 0.092 & 0.99 & 1.000 & 1.000 \\
\hline Impact & 6.6 & 5 & 0.251 & 0.99 & 0.99 & 0.97 & 0.99 & 0.032 & 1.3 & 0.99 & 0.99 & 0.99 \\
\hline Trust & 0.000 & & & & 1.000 & & 1.000 & & & & 1.000 & 1.000 \\
\hline $\begin{array}{l}\text { Acceptable } \\
\text { limit * }\end{array}$ & - & - & $x>0.05$ & $x>0.90$ & $x \approx 1$ & $x>0.90$ & $x>0.90$ & $x<0.10$ & $1<x<5$ & $x>0.90$ & $x>0.90$ & $x>0.90$ \\
\hline
\end{tabular}

The second-order confirmatory factor analysis model for analyzing the hidden variable of state investment and rural empowerment

The final model of measuring and estimating the hidden variable of state investment and rural empowerment based on 2 variables of state investment and rural empowerment and based on 9 observed ecological, economic, social, physical-spatial, self-determination, competence, meaning, impact and trust dimensions, which itself consisted of 39 different components, were estimated and measured in Amos environment. Figure 5 shows this model, which is a second-order confirmatory factor analysis model, with non-standard estimates of path coefficients and variances of hidden variables. As can be seen in the figure, several error covariance estimates are also considered as a free parameter to further improve the model fit indices, which have no theoretical meaning. This time, the estimation of error variances as well as the defined covariance between the errors are small. In addition, the variances of the latent error variable as well as the main variables are in all cases positive values, which is a reason for the validity of the model. In general, the greater the common variance between a hidden variable and an observed variable, the smaller the measurement error.

In the following, we show the standard path coefficients between the hidden variables with each other and the observed variables with the hidden variables, which are in fact the main and important part of all analyses.
Figure 6 and Table 4 provide the importance and especially the possibility of comparing them.

As can be seen, all but one or two standard path coefficients show high values, and this is more severe in relation to the observed variable factor loads of rural empowerment compared to state investment.

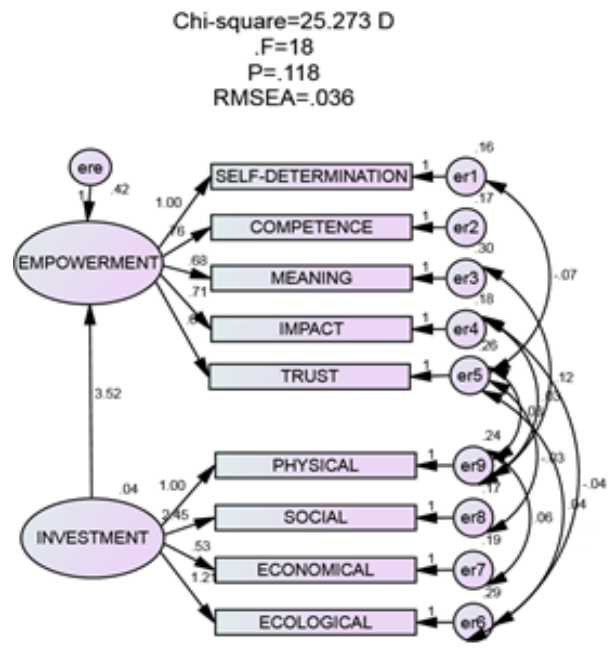

Figure 5. Structural model of second-order confirmatory factor analysis for estimating and analyzing the role of state investment in empowering villagers along with non-standard estimates 


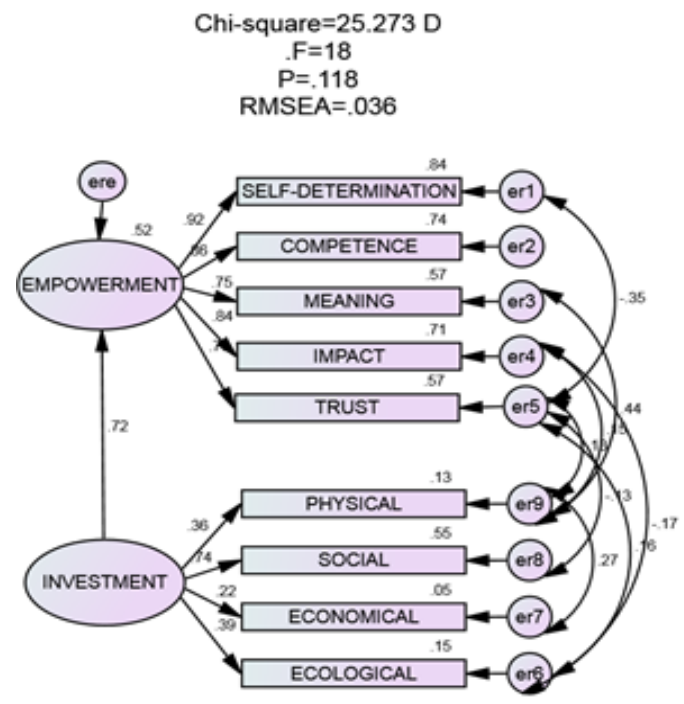

Figure 6. Standard estimates of path coefficients in the final structural model of the role of state investment in rural empowerment

In general, by eliminating the effects of measurement errors in the structural equation approach, the coefficient of effectiveness of rural empowerment from the five components of self-determination, competence, impact, trust and meaning, in other words, correlation coefficients between empowerment and each of the above components, the results were $0.92,0.86,0.84,0.76$ and 0.75 , respectively. Also, the coefficient of influence of state investment from four components of social, ecological, physical-spatial and economic, in other words, correlation coefficients between state investment and each of the above components are equal to $0.74,0.39$, 0.36 and 0.22 , respectively, and finally the coefficient of effectiveness of rural empowerment from the investment component, in other words, the correlation coefficients between rural empowerment and state investment was 0.72 .

Reference to standard error estimates, critical ratios and significance levels also shows that all of these standard estimates are $99 \%$ significant.

Table 4. Standard estimates and significance level of factor loads of sub-scale components of investment and rural empowerment

\begin{tabular}{|c|c|c|c|c|c|c|}
\hline & & \multicolumn{5}{|c|}{ Measured variables and indicators (observed indicators) } \\
\hline & & component & Estimate & S.E. & C.R. & $\mathbf{P}$ \\
\hline \multirow{4}{*}{ Investment } & $--->$ & Ecological & 1.212 & .285 & 4.249 & $* * *$ \\
\hline & $--->$ & Economic & .529 & .157 & 3.376 & $* * *$ \\
\hline & $--->$ & Social & 2.448 & .492 & 4.979 & $* * *$ \\
\hline & $--->$ & Physical-spatial & 1.000 & & & \\
\hline \multirow{5}{*}{ Empowerment } & $--->$ & Self-determination & 1.000 & & & \\
\hline & $--->$ & Competence & .764 & .034 & 22.444 & $* * *$ \\
\hline & $--->$ & Meaning & .680 & .039 & 17.413 & $* * *$ \\
\hline & $--->$ & Impact & .715 & .033 & 21.376 & $* * *$ \\
\hline & $--->$ & Trust & .639 & .042 & 15.242 & $* * *$ \\
\hline Investment & $--->$ & Empowerment & 3.521 & .671 & 5.247 & $* * *$ \\
\hline
\end{tabular}


Finally, the fit indices of this model along with the proposed benchmark values for their evaluation are listed in Table 5. Chi-square values of this model have increased compared to previous measurement models. This is due to the greater difference of the variance-covariance matrices reproduced based on the parameters estimated with the covariance matrix of the variance observed in this model compared to previous measurement models, but this difference is never significant $(\mathrm{P}$-value $=0.118)$. And the whole model is approved. Adding more free parameters to the model (often covariances between errors such as that defined between self-determination and trust and the like) has further improved this index. However, it should be noted that by adding each free parameter, one unit of the degree of freedom of the model decreases, and this will cause some other fit indices to be further away from the relevant standard values. In the model under discussion, all other indicators are in a very good condition compared to the standard values and all confirm the validity of the model.

Finally, it should be said that the model fit indices have been evaluated at an appropriate level, which indicates the complete fit of the research model. In other words, all measures of the present study have a high correlation or covariance with respect to their independent variable.

The final structural model includes coefficients related to the direct effect of the investment variable as well as the indirect effect of the observed components on the latent dependent variable of rural empowerment. It is noteworthy that the estimates or regression coefficients of the direct effect between the observed variables and the corresponding scales in the final structural model are somewhat different from the estimates obtained from previous measurement models: First, these differences are due to the fact that in the final structural model, all the observed variables are present together and in estimating the coefficient of each variable, in addition to the relevant subscales, they are also effective in loading other subscales; Second, the importance of measurement models is only to obtain valid scales or subscales to evaluate and measure the main dependent scale or variable. And the extent to which the relationship and the actual effect of the observed variables on the dependent latent variable show the coefficients or indirect effects of the structural model. Accordingly, Table 6 shows the standard regression coefficients or the final direct and indirect effects of the observed variables on the main hidden dependent variable (the role of investment in rural empowerment).

The noteworthy thing about these coefficients is that a significant level is reported for all final direct effects based on standard and critical ratio errors. These significance levels for all final direct effects are less than 0.01 , which indicates the significance of all reported direct effects at the $99 \%$ level. Critical ratios and therefore significant levels for indirect effect coefficients are not calculated and reported. But the standard values of these coefficients, since they are not dependent on the scale, make it possible to compare the effects of the observed variables on the final dependent variable (rural empowerment). Therefore, it can be said that the most indirect effect of state investment is related to social investment, ecological investment, physical-spatial investment and finally economic investment, respectively.

Finally, the findings of field studies show that there is a significant and high relationship between investment and empowerment of villagers. Statistical data from rural household questionnaires $(n=316)$ indicate a significant relationship between the two variables. Based on the research findings, there is a significant relationship between the two variables of investment and rural empowerment, less than 0.05 (alpha less than 0.05) and a strong, positive and direct relationship between the two variables, so that the correlation coefficient between the two above variables was 0.507 . According to the findings of Table 7, it can be said that the better the investment in the villages, the better the empowerment of the villagers will be and vice versa, or the less the investment in the villages, the less empowerment of the villagers will be In other words, as a result of the direct correlation between the two research variables, with an increase of $\mathrm{X}$, we will also have an increase of $Y$.

Table 5. Test of the final structural model of the role of state investment in empowering villagers based on nine scales

\begin{tabular}{|c|c|c|c|c|c|c|c|c|c|c|c|c|}
\hline & \multicolumn{12}{|c|}{ Fit indicators } \\
\hline & $\sum_{U}^{z}$ & 㟔 & $a$ & $\Xi$ & $\overline{\bar{z}}$ & 苛 & 芯 & $\underset{\sim}{\overleftarrow{\sim}}$ & 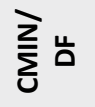 & $\underset{\check{\alpha}}{\bar{\pi}}$ & $\bar{u}$ & ㅍ \\
\hline $\begin{array}{l}\text { Experimental values of } \\
\text { the model }\end{array}$ & 25.27 & 18 & 0.118 & 0.98 & 0.98 & 0.95 & 0.98 & 0.036 & 1.40 & 0.96 & 0.99 & 0.99 \\
\hline Acceptable limit & - & - & $x>0.05$ & $x>0.90$ & $x \approx 1$ & $x>0.90$ & $x>0.90$ & $x<0.10$ & $1<x<5$ & $x>0.90$ & $x>0.90$ & $x>0.90$ \\
\hline
\end{tabular}


Table 6. General effects (direct and indirect) of the observed variables on state investment and rural empowerment

\begin{tabular}{ccc}
\hline & Investment & Empowerment \\
\hline Empowerment & 0.718 & 0 \\
Ecological & 0.390 & 0 \\
Economic & 0.223 & 0 \\
Social & 0.744 & 0 \\
Physical-spatial & 0.359 & 0 \\
Trust & 0.544 & 0.757 \\
Impact & 0.606 & 0.843 \\
Meaning & 0.540 & 0.752 \\
Competence & 0.619 & 0.862 \\
Self-determination & 0.660 & 0.919 \\
\hline
\end{tabular}

Table 7. The correlation coefficient between investment factor and rural empowerment

\begin{tabular}{cccc}
\hline & & Empowerment & Investment \\
\hline & Pearson Correlation & 1 & $.312^{* *}$ \\
Empowerment & Sig. (2-tailed) & & .000 \\
& $\mathrm{~N}$ & 316 & 316 \\
Investment & Pearson Correlation & $.312^{* *}$ & 1 \\
& Sig. (2-tailed) & .000 & 316 \\
\hline **. Correlation is significant at the 0.01 level (2-tailed). & 316 & O JSR
\end{tabular}

\section{Discussion}

In Iran, rural development is a process with the dominant role of the state. Since the formation of the centralized state in Iran and after 1927, planning has started in its current form, and after 60 years, 12 programs have been prepared in the country, 11 of which have been implemented.

Many years have been spent implementing different growth and development models and many failures have occurred. In recent decades, new development programs have introduced a new model of rural development that seeks to revitalize rural areas by improving and increasing the value of local resources, both natural and human, according to the priorities and preferences of the local community. In the strict sense of the word, the new paradigm is based on the principle of empowerment of rural communities.

If the village is assumed as a system, the introduction of a new variable will lead to changes in this system. The state expects these changes to empower villagers. But there is no requirement that the influx of investment into the villages leads to the empowerment of the villagers and it can have quite the opposite effect. But was what actually took place in the country's villages homogeneous with the demands and goals of the programs? In other words, considering the high volume of credits that are spent every year in rural settlements, the question can be raised that what does investing in rural settlements have to do with empowering the villagers?

Findings from field studies indicate a strong, positive and direct relationship between the two variables of investment and rural empowerment $(P=0.000)$. In this sense, it increases with increasing investment in rural empowerment. Analysis of the findings of the structural equation model showed that state investment with a factor load of 0.072 has an impact on rural empowerment and the model is approved with RMSEA $=0.036$.

Therefore, rural empowerment is studied as a new approach in the development of rural areas, with a systematic, integrated and combined perspective to determine self-determination, competence, impact, significance and trust as the driving force of empowerment in rural communities. In this way, the right to development and 
honorable life in rural areas can be realized objectively. In fact, due to their structural and functional nature, villages are related to all factors of human life and the challenges ahead cannot be solved with a one-dimensional view. In the combined view, all factors are effective in empowering the villagers and the absence of one of the factors challenges the process of empowering rural communities.

According to what has been said, the results of the article provide some strategic points: Lack of careful study and evaluation of developments in rural areas after the arrival of investments and on the other hand different perceptions of the concepts of capacity building and empowerment in practice has caused problems in rural society to stay.

Thus, the suggestions derived from the research are significant:

\section{Conceptual proposal:}

- Designing a conceptual model of indigenous and binding sustainable rural development strategy in arid areas

- In planning sustainable rural projects, it is necessary to develop development empowerment instead of service attitude.

- In the executive methods, instead of the state authoritarian method, the state facilitation method and local institution building should be replaced.

\section{Cognitive suggestion:}

- In the stage of choosing the planning method and determining the plans beyond the behavior of administrative and bureaucratic rationality, the participation of all stakeholders is essential.

- Localization of the process of development and empowerment of people with popular rationality

\section{Acknowledgements}

This research did not receive any specific grant from funding agencies in the public, commercial, or not-forprofit sectors.

\section{Conflict of Interest}

The authors declared no conflicts of interest.

\section{References}

Amir Ahmadi, H. (2002). Political Society, Civil Society and National Development, Naghsh and Negar Publications. (in Farsi)

Amundsen, S., \& Martinsen, Q.L. (2015). Linking empowering leadership to job satisfaction, work effort, and creativity: The role of self-leadership and Psychological Empowerment, Journal of Leadership \& Organizational Studies, 22

Assche, K.V., Duineveld, M., \& Beunen, R. (2014).Power and contingency in Planning, Environment and Planning,46(10), 2385 .

Azad Armaki, T. (2000). Modernization Thoughts in Iran, University of Tehran Press. (in Farsi)

Chen, Z., Li, L., Li, T. (2016). The organizational evolution, systematic construction and empowerment of Langde Miao $s$ community tourism, Tourism Management, Vol. 28, No. 6, $\mathrm{p}, 78$.

Cumming, T.G., \& Worly, C.G. (2014). Organization Development and Change, Cengage Learning.

Ebrahim Bay Salami, Gh. (2007). Government-Society Relations from a Sociological Perspective, Social Science Letters, 151, 175. (in Farsi)

Evans, P. (2001). Embedded autonomy states and industrial transformation, translated by Abbas Zandbaf and Abbas Mokhber, Tarh-e No Publications. (in Farsi)

Fernandez, S., \& Moldogaziev, T. (2015). Employee Empowerment and Job Satisfaction in the U.S. Federal Bureaucracy: A Self-Determination Theory 16 Perspective, the American Review of Public Administration July 1, 45(4), 375-401.

Giampiccoli, A., \& Mtapuri, O. (2012). Community-based tourism: An exploration of the concept (s) from a political perspective, Tourism Review International, 16(1), 29.

Healey, P. (2000). Planning theory and urban and regional dynamics: a comment on Yiftachel and Huxley, Urban and Regional Research, 24(4), 917.

Hooman, H. (2005). Reserch Methodology in Behavioral Sciences, samt.

Jalaee Poor, H., Azad Armaki, T., Kalaantari, GH., \& Baqaee Saraabi, A. (2014). Evolution of State-Society Relations Types in the Process of Urban Development: From Dependency to Empowerment, Urban and rural management, 13(35), pp. 132-121. (in Farsi)

Kohli, A. (2004). State-Directed development, Political Power and Industrialization in the Global Periphery, Cambridge University Press. 
Kumar, A. (2004). The Development State in History and in the Twentieth Century, Regency Publications.

Michalek, J., \& Zarnekow, N. (2012). Application of the Rural Development Index to Analysis of Rural Regions in Poland and Slovakia, Social Indicators Research,105, 1.

Moseley, M. (2003). Rural Development, Sage, London.

Rand, A. (2004). The Nature of government, center for civil society, P1

Razavi, N. (2011). The Call for Children's Participation in Rura Empowerment and its Fundamentals, housing and rural environment, 133, pp. 28-29. (in Farsi)

Rifkin, S.B. (2003). A Framework Linking Community Empowerment and Health Equity: It is Matter of CHOICE, Journal of Health Population Nutrition, 21, 168

Roknedin Eftekhari, A., \& Heydari Sarban, V. (2017). Rural Empowerment (Fundamental Principles, Approaches, Theories and Experiences), Tarbiat Modares University Press. Tehran. (in Farsi)

Rossberger, R.J., Krause, D.E. (2014). Participative and TeamOriented Leadership Styles, Countries' Education Level, and National Innovation, Cross-Cultural Research, 49(1), 20.

Saeedi, A., \& Darabi, H. (2006). The role of government construction investment in stabilizing the rural population, Geographical Research, 83, p.53. (in Farsi)

Saraie, H. (2003). An Introduction to Sampling in Research, samt

Shafiei Sabet, N., Hosseini Hasil, P. \& Rahbari, M. (2019). Management, Empowerment of Local Stakeholders and Physical Transformation of Rural Settlements (Case Study: Semnan Province), Housing and Rural Environment, 165, pp. 132-113. (in Farsi)

Shafiei Sabet, N., Rahbari, M. (2018). Rural Management, Rural Empowerment and Environmental Developments in Rural Settlements (Case Study: Semnan Province), 13th Congress of the Geographical Association of Iran, p. 726. (in Farsi)

Shahraki, A. (2014). Spatial analysis of barriers and limitations of economic and social empowerment of rural households, case study: Clients under the auspices of the Relief Committee in Sistan region, Master Thesis in Geography and Rural Planning, Zabol University. (in Farsi)

Shakoori, A. (2005). Agricultural Development Policies in Iran, Samat Publications, Tehran. (in Farsi)

Shakoori, A. (2004). Planning and Agricultural Development in Iran, critical Middle Eastern Studies, Vol.15, No.3, p242.

Sharma, S., \& Gupta, A. (2017). The Everyday lives and coping strategies of women in Delhi; Discerning roots of Psychological Empowerment-An Ethnographic Study, International Journal of Indian Psychology, 4(2), 12.

Simard, M., Guimond, L., \& Ve'zina, J. (2017). Neo-rural populations and their relations with local decision makers in rural Que'bec: collaboration or conflict", GeoJournal, Published online.

Statistics Center of Iran. (2016). General population and housing census of Aran and Bidgol counties. (in Farsi)
Statistics Center of Iran. (2016). General population and housing census of Kashan counties. (in Farsi)

Steel, M. (2010). Oxford Word power Dictionary, Oxford University Press. New York.

Waas, T., Hugé, J., Block, T., Wright, T., Benitez-Capistros, F., Verbruggen, A. (2014). Sustainability assessment and indicators: Tools in a decision-making strategy for sustainable development, Sustainability, 6(9), 5512.

Waligo, V.M., Clarke, J., \& Hawkins, R. (2013). Implementing sustainable tourism: A multistakeholder involvement management framework. Tourism Management, 36, 342.

Woods, M. (2011). Rural Geography (Processes, Responses and Experiences in Rural Restructuring), translated by Mohammad Reza Rezvani and Samet Farhadi, University of Tehran Press. (in Farsi)

Zasada, I., Häfner, K., Schaller, L., Van Zanten, B. T., Lefebvre, M., Malak-Rawlikowska, A., \& Zavalloni, M. (2017). A conceptual model to integrate the regional context in landscape policy, management and contribution to rural development: Literature review and European case study evidence. Geoforum, 82,1 . 
